\title{
Post Dural Puncture Headache After Spinal Anaesthesia and Chance Of Spinal Failure: A Comparative Study Using 23 G Quincke, 25G Quincke, And 25 G Whitacre Needle
}

\author{
Dr. Simeen Usmani MBBS, DNB. Dr. Jamal Azmat* MBBS, MD. \\ Prof. Shaheen Jameel MBBS, MD. Dr. Sirajuddin P.G. Student
}

\begin{abstract}
Objective: To compare the frequency and severity of postdural puncture headache (PDPH) and technical difficulties in patient of age 18 -60 year planed for lower abdominal surgery.

Method: 75 patient of age group 18-60 years with ASA I and ASA II, scheduled for abdominal surgery in spinal anaesthesia were taken and were divided into three groups of 25 patient each, accordingly to the size and shape of the needle, 23 G Quincke (Group I), 25 G Quincke (Group II) and 25 G Whitacre (Group III). Parameters observed are frequency of PDPH, severity of PDPH and technical problem in term of number of attempt and failure rate.

Result: The incidence of PDPH was $24 \%$ in Group I, $12 \%$ in Group II, and $4 \%$ in Group III. ( $p$-value >0.05), Group III patient were having very mild headache. Subarachnoid space was located successfully in first attempt in $92 \%$ cases in Group I, 52\% cases in Group II, 40\% cases in Group III .
\end{abstract}

Conclusion: $25 \mathrm{G}$ Whitacre needle seems to be suitable choice in patient because of its ease of handling with low incidence PDPH.

\section{Introduction}

August Bier (1898) introduced spinal analgesia in clinical practice, since then the technique has been widely practice to provide Anesthesia for lower abdominal surgery. It is simple to introduce, rapid in effect and produces excellent operating condition, ${ }^{1}$ less need of postoperative monitoring and provides adequate postoperative analgesia. ${ }^{2}$ Post dural puncture headache (PDPH) is a well known complication of spinal anaesthesia, especially in younger patient. ${ }^{3}$ Although it may be transient and self limiting sometimes it may persist for hours or weeks and can be intolerable, leading to prolonged hospital stay and increased cost. ${ }^{4} \mathrm{Factor}$ reported to influence the incidence of PDPH are age ,sex, pregnancy, previous history of PDPH ${ }^{5}$, needle size' ${ }^{5,6}$, needle tip shape ${ }^{5,6}$ bevel orientation to the dual fiber ${ }^{5-7}$ The two strategies which decreases the incidence of PDPH are, to reduce gauge of the needle, and to change the design of needle tip .Studies have indicated that decreasing the needle gauge reduces the incidence of PDPH ; however, it increases the technical difficulty, leading to increase in failure rate ${ }^{8-12}$.

The purpose of this study is to show that, how thin needle can be used in clinical practice to achieve the lower incidence of PDPH without compromising success rate.

The present study was undertaken to compare the technical difficulty, spinal failure and PDPH by using the three needle, 23G, 25G, Quincke, and 25G Whitacre needle in three groups.

\section{Method}

The present study was conducted in OT and informed consent was obtained from 75 patients. American Society of Anesthesiologist (ASA Group I and II) of either sex in the age group between 18 to 60 years who receive spinal anesthesia, to undergo lower abdominal surgery were taken. Exclusion criteria were, Infection at the site of needle insertion, coagulation disorders and neurological symptoms. Pre anesthetic checkup of all patients prior to 24 hours of surgery was done and they were informed of the procedure. Detailed history of the patients were taken and recorded, all patients were premeditated with 1 tab of Alprazolam $0.25 \mathrm{mg}$ at bed time, and kept NPO for 6 hours. On arrival in the operation theatre preloading with 10-15 ml $/ \mathrm{kg}$ of Ringer Lactate over 15 minute was done, after all aseptic precaution spinal anaesthesia was administered in L3-L4 space with $3.0-3.5 \mathrm{ml}$ of $0.5 \%$ heavy Bupivicain, through either $23 \mathrm{G}$ Quincke, $25 \mathrm{G}$ Quicke or $25 \mathrm{G}$ Whitacre needle using midline approach in sitting position. The number of attempts given for spinal block were recorded, all patient were administered 5-6 lite/min of $\mathrm{O}_{2}$ intraoperatively with Hudson mask. BP, Heart rate, ECG, and oxygen saturation were monitored continuously every 5 minutes during surgery, 15 minute during immediate postoperative period for 2 hour and than 2 hourly for 24 hours. In case if patient developed hypotension it was managed by intravenous crystalloid. Hypotension associated with bradycardia was managed with intravenous atropine $15 \mu \mathrm{gm} / \mathrm{kg}$. If hypotension did not respond to I.V. fluid, injection Mephentamine $1 \mathrm{ml}(6 \mathrm{mg})$ was used as bolus. 
Postoperatively all patient were assessed 24 hourly for next 2 days. Resident monitoring the patient was blinded to the type and size of the needle .PDPH was defined as headache which was aggravated in upright position and relieved in the supine positions. Severity of PDPH was graded as mild, moderate and severe.

\section{Criteria of Post Dural puncture headache:}

1. Occurred after mobilization

2. Aggravated by erect or sitting position, coughing, sneezing or staring and relieved by lying flat.

3. It may be localized in occipital, frontal or it may be generalized.

\section{Severity of headache was assessed on 1-4 scale. (Crocker 1976)}

1. Mild headache, which permits long periods of sitting / erect position with no other symptoms.

2. Moderate headache, which made it difficult for the patient to stay upright for more than half an hour. Occasionally accompanied by nausea, vomiting, auditory and ocular symptoms.

3. Intense headache immediately upon getting up from bed, alleviated while horizontal in bed. Often accompanied by nausea, vomiting, ocular and auditory symptoms.

4. Headache that occurred even while lying horizontal in bed and greatly aggravated immediately upon standing upright. Eating is impossible because of nausea and vomiting.

The primary objective of the study was to find out any difference in the incidence of PDPH between the three groups. The secondary objective was to find out the incidence of failure of lumber puncture and the number of attempts required achieving lumber puncture.

Quantitative variables were expressed as Mean \pm SD (standard deviation) while qualitative variables were expressed as percentage. PDPH was analyzed using Chi square test. $\mathrm{P}-$ value $<0.05$ was considered significant.

\section{Result}

We studied 75 patients, ASA physical status I -II, age 20 to 60 years, undergoing spinal anesthesia for lower abdominal surgery using $23 \mathrm{G}$ Quincke ,25 G ,Quincke, and 25G whitacre spinal Needles.

Table -1: Dermographic data of the patients.

\begin{tabular}{|c|c|c|c|c|}
\hline & Group I & Group II & Group III & \multirow[b]{2}{*}{$p$-value } \\
\hline & 23 G Quincke & 25G Quincke & 25 G Whitcare & \\
\hline $\begin{array}{l}\text { Age }(y r s) \\
\text { Mean } \pm \text { SD }\end{array}$ & $44.48 \pm 12.7$ & $41.6 \pm 10.1$ & $44.1 \pm 17.7$ & NS \\
\hline $\begin{array}{l}\text { Weight } \\
\text { Mean } \pm \text { SD }\end{array}$ & $61.4 \pm 15.6$ & $60.96 \pm 11.3$ & $64.6 \pm 11.8$ & NS \\
\hline $\operatorname{Sex}(\mathrm{M} / \mathrm{F})$ & $4 / 21$ & $6 / 19$ & $10 / 15$ & \\
\hline Physical Status & & & & NS \\
\hline ASA I & & & & \\
\hline ASA II & & & & \\
\hline
\end{tabular}

ASA I = Normal healthy patient

ASA II = A patient with mild systemic disease with no functional limitation.

Table -2: Frequency of PDPH

\begin{tabular}{|l|l|l|l|c|}
\hline \multirow{2}{*}{ PDPH } & Group I & Group II & Group 3 & \multirow{2}{*}{ p-value } \\
\cline { 2 - 4 } & 23 G Quincke n(\%) & $\begin{array}{l}\text { 25 G Quincke } \\
\mathbf{n}(\%)\end{array}$ & $\begin{array}{l}\text { 25 G Whitacre } \\
\mathbf{n}(\%)\end{array}$ & NS \\
\hline Present & $6(24 \%)$ & $3(12 \%)$ & I $(4 \%)$ & \\
\hline Absent & $19(76 \%)$ & $22(88 \%)$ & $24(96 \%)$ & \\
\hline
\end{tabular}

Table -3 : Severity of PDPH Total incidence

\begin{tabular}{|l|l|l|l|c|}
\hline \multirow{4}{*}{ PDPH } & Group I & Group II & Group III & \multirow{2}{*}{$\boldsymbol{p}$-value } \\
\cline { 2 - 4 } & $\begin{array}{l}\text { 23G Quincke } \\
\text { n (\%) }\end{array}$ & $\begin{array}{l}\text { 25 GQuincke } \\
\text { n(\%) }\end{array}$ & $\begin{array}{l}\text { 25 G Whitacre } \\
\text { n (\%) }\end{array}$ & \multirow{2}{*}{ NS } \\
\hline Mild & $4(16 \%)$ & $3(12 \%)$ & $1(4 \%)$ & \\
\hline Moderate & $1(4 \%)$ & 0 & 0 & \\
\hline Severe & $1(4 \%)$ & 0 & 0 & \\
\hline Duration & & & 1 & \\
\hline$<24$ hrs & 5 & 1 & & \\
\hline $25-48$ hours & & 2 & & \\
\hline$>48$ hours & 1 & & & \\
\hline
\end{tabular}


Table 4 : Technical problem

\begin{tabular}{|l|l|l|l|c|}
\hline & Group I & Group II & Group III & \multirow{2}{*}{} \\
\cline { 2 - 4 } & $\begin{array}{l}\text { 23G Quincke } \\
\text { n(\%) }\end{array}$ & $\begin{array}{l}\text { 25 GQuincke } \\
\text { n(\%) }\end{array}$ & $\begin{array}{l}\text { 25 G Whitacre } \\
\text { n(\%) }\end{array}$ & NS \\
\hline First attempt & $23(92 \%)$ & $13(52 \%)$ & $10(40 \%)$ & \\
\hline Second attempt & $1(4 \%)$ & $8(32 \%)$ & $11(44 \%)$ & \\
\hline Third attempt & $1(4 \%)$ Partial effect & $4(16 \%)$ & $4(16 \%)$ & \\
\hline
\end{tabular}

\section{Discussion}

In 1898, Karl August Bier, a German surgeon and his assistant were the first to report the symptoms associated with PDPH ${ }^{13)}$ Bier presumed that the headache was due to loss of CSF.

The present trend of the anesthetic technique for lower abdominal surgery in the world wide is Subarachnoid block (SAB), because it is safe, easier to perform, high degree of success rate, and required less drug and monitoring ${ }^{1-3.3}$

Headache after Dural puncture is a complication of spinal anesthesia and it believed to result from leakage of CSF both at the time of dural puncture and continuous leak afterward.

Dural puncture headache depends upon its association with body position, the pain is aggravated by sitting or standing and relieved or decreased by lying down ${ }^{13}$

Besides these factors, post dural headache is related to the size as well as type of the spinal needle used ${ }^{14}$ it is progressively reduced with use of thinner and pencil tip needles, ${ }^{15,16}$ but attempt to eliminate it by using needles as small as $29 \mathrm{G}$ to $32 \mathrm{G}$ have limited success rate. They are associated with high failure rates or multiple attempt. ${ }^{9,17}$ If there are multiple holes in the dura, no matter how small, they will increases the incidence of headache and defeat the purpose of using the smaller gauge needle ${ }^{5,18}$

In the current study, successful subarachnoid puncture at first attempt decreases progressively with smaller gauge needle, and in pencil point needle more force is required. ${ }^{19}$

To overcome the problem PDPH, Hart and Whitacre in 1950, designed the first pencil point needle and claimed to decrease of PDPH from 5 to $2 \%{ }^{20}$. In our study out of 75 patient, 10 were complicated by headache postoperatively, the overall incidence of PDPH was $24 \%$ In Group I, $12 \%$ In group II and $4 \%$ in group III . The difference in PDPH between group was not statistically significant.

The mean duration of headache was found to be 24 to 78 hours. In 7 out of 10 patients, the duration of headache lasted less than 24 hours. The headache was mild to moderate in nature after dural pucture and was relieved by rest, hydration and analgesics. Study by Anuja et al have similar results as our study. In the study by Shutt et $\mathrm{al}^{8}$, onset of headache was from 18 to 57 hour after dural puncture, which was higher than our study.

The overall incidence of PDPH has varied from $0 \%$ to $37.2 \%$, As reported by various authors ${ }^{8}$. Shah VR \& Bhosle $\mathrm{GP}^{20}$ data showed that a $25 \mathrm{G}$ Whitcare needle would be best choice with regard to high success rate low PDPH, they used $25 \mathrm{G}$ Quincke needle and concluded that incidence of PDPH was $14 \%$, in our study it was $12 \%$.The results of these study were similar to our result but $23 \mathrm{G}$ needle was technically easy to use with $96 \%$ success rate in single attempt, but in case of $25 \mathrm{G}$ Quinke single attempt success rate are $64 \%$.

Hwang et al ${ }^{22}$ in their study with in 93 caesarean section patients, using $25 \mathrm{G}$ Whitacre and $25 \mathrm{G}$ Quincke found that in case of $25 \mathrm{G}$ Whicare there was lower incidence of PDPH, but their results were not statistically significant and our results were similar to that study.

Vallego et $\mathrm{al}^{23}$ in their study found that 25 Quincke needle has a high frequency of PDPH, as compared to the pencil point needle, our result are similar to this. Nevertheless, they concluded that in addition to PDPH, cost consideration, ease of insertion, rate of CSF flow, and the ease with which the needle bends or breaks when excessive forward force is applied, to be taken into consideration while choosing the spinal needle

Kang SB and his colleagues ${ }^{24}$ noticed that some PDPH were severe enough to require an epidural blood patch ,the therapy of epidural patch is invasive, cumbersome and hazardous, thus there is no doubt , that prevention is a better option. One patient of Group 1 had severe headache, associated with nausea and vomiting and it persisted for 7 days, but we did not used epidural patch and was treated by hydration, bed rest, and analgesic. Cruik Shank etal ${ }^{21}$ could not demonstrate any significant difference in CSF leakage by aligning the bevel of the needle either parallel or across the dural fibers, and their observation was that the CSF leakage rate was related to the needle size. However, we chose to insert the Quincke needle with the bevel parallel to the longitudinal axis of the spinal cord, as per the classical teaching.

There are few studies which examine the technical difficulties involved in the use of different spinal needle. In the study by Shutt et al (1992) the failure rate was $2 \%$ with $23 \mathrm{G}$ needle .In our study failure rate was $4 \%$ with $23 \mathrm{G}$ needle and $96 \%$ case were successfull in first attempt. This $4 \%$ failure rate could be due to any technical problem ,or small sample size . But by using $25 \mathrm{G}$ needle, success rate was $100 \%$, but number of attempt was variable. $64 \%$ patient required $1^{\text {st }}$ attempt and $16 \%$ patient were successful in 2 nd attempt and $16 \%$ patients required multiple attempt. In case of whitacre $40 \%$ patient had required one attempt , $44 \%$ required two 
attempts , and $16 \%$ patient required three attempts by the same anesthetist with enough experience of spinal anesthesia.

Bano et al ${ }^{25}$ Compared the Whitacre group, frequency of postdural puncture headache was significantly higher in Quincke group $\left({ }^{*} \mathrm{p}=0.015\right)$, while the overall occurrence of non-postdural puncture headache (PDPH) did not differ significantly between two groups ( $\mathrm{p}=0.736$ ). Most of PDPH developed on 2 nd postoperative day, were mild in nature and resolved within 48 hours of their onset. There was no significant difference in the failure rate of spinal anesthesia in both groups $(\mathrm{p}=0.149)$. In our study the frequency of headache was $12 \%$ in in Group II and $4 \%$ in Group III (p-1.2) which was not statistically significant. In our study there was no statistically significant difference in the failure rate of spinal anesthesia in the three groups .

Vishal Joshi ${ }^{26}$ et al concluded in their study that incidence of PDPH using $25 \mathrm{~g}$ needle was $8 \%$, Jan Mohammad et al $8.3 \%{ }^{27}$, Ross et al $9 \%^{7}$. These results are not comparable to our study. Anuja et al found out that incidence was $10 \%$ with $23 \mathrm{~g}$ needle .In our study it was $24 \%$ which was quite higher.

\section{Conclusion}

Pencil point needle are associated with lower incidence of PDPH compared to Quincke cutting needles. Whitacre 25G needles appears to the preferred choice in terms of high success rate, and low incidence of PDPH. By Whitacre number of attempt could be increased, however, the cost of the Whitacre spinal needles has to be weighed against the risk of PDPH, the associated cost of a longer hospital stay, and the hazardous therapy of an epidural blood patch.

\section{References}

[1]. Ranasinghe JS, Steadmann J , Toyama T, lai M . Combined spinal epidural anaesthesia is better than spinal or epidural alone for caesarean delivery . Br J Anaesthesia 2003;9(2); 299- 300.

[2]. Fauzia B, Saleem S, Safia Z, NabeelaR, Intrathacal fentanyl as ajunct to heyperbaric Bupivacaine in spinal anesthesia for Caesarean Section. JCPSP 2006; 16 (2):87- 90.

[3]. Hawkins JL, koonin LM, Palmer SK, Gibbs CP, Anesthesia related deaths during obstetric delivery in the United States .Anesthesiology 1997; 86(2); 674-7

[4]. Lybecker H, Djernes M, Schmidt JF. Postdural puncture headache. Acta Anaesthesiol Scand 1995;39:605-12.

[5]. Lybecker H, Moller JT, May O, Nielsen HK. Incidence and prediction of post dural puncture headache: a prospective study of 1021 spinal anesthesias. Anesth Analg 1990;70:389-94.

[6]. Halpern S, Preston R. Postdural puncture headache and spinal needle design - metaanalyses. Anesth 1994;81:1376-83.

[7]. Ross BK, Chadwick HS, Mancuso JJ, Benedetti C. Sprotte needle for obstetric anesthesia: decreased incidence of postdural puncture headache. Reg Anesth 1992;17:29-33.=

[8]. Shutt LE, Valentine SJ, Wee MYK, et al. Spinal anaesthesia for Caesarean section: comparison of 22-gauge and 25-gauge Whitacre needles with 26-gauge Quincke needles. Br J Anaesth 1992;69:589-94.

[9]. Lynch J, Arhelger S, Krings EI. Post-dural puncture headache in young orthopaedic in patients: comparison of a 0.33 mm (29gauge) Quincke-type with a $0.7 \mathrm{~mm}$ (22-gauge) Whitacre spinal needle in 200 patients. Acta Anaesthesiol Scand 1992;36:58-61.

[10]. Tarkkila PJ. Incidence and causes of failed spinal anesthetics in a university hospital: a prospective study. Reg Anesth 1991;16:4851.

[11]. Lynch J, Kasper SM, Strick K, et al. The use of Quincke and Whitacre 27-gauge needles in orthopedic patients: incidence of failed spinal anesthesia and postdural puncture headache. Anesth Analg 1994;79:124-8.

[12]. Sayeed YG, Sosis M, Braverman B, Ivankovich AD. An in vitro investigation of the relationship between spinal needle design and failed spinal anesthesia. Reg Anesth 1993;18:85.

[13]. Wulf HFW. The centennial of spinal anesthesia. Anesthesiology 1998;89:500-6.

[14]. Garry M, Davies S,Failure of regional blockade for Caesarean section . Int J Obstet Anesth 2002;11;1376-83.

[15]. Grieff J , Cousins MJ. Sub-arachnoids and extradural anaesthesia. In NimmoWS, Row Botham DJ, Smith G, Anesthesia $2^{\text {nd }}$ edition , Blackwell Scientific publication Londan 1994; p1411-54

[16]. 16.Gunadyan B, Karaca G. Prevention strategy for postdural puncture headache . Acta Anesthesiol Bel 2006;57(2):163 -5.

[17]. Hoskin MF et.al Spinal anaesthesia--the current trend towards narrow gauge atraumatic (pencil point) needles. Case reports and review. Anaesth Intensive Care. 1998 Feb; 26(1):96-106.

[18]. Seeberger MD, Kaufmann M, Staender S, et al. Repeated dural punctures increase the incidence of postdural puncture headache. Anesth Analg 1996;82:302-5.

[19]. Westbrook JL, Uncles DR, Sitzman BT, et al. Comparison of the force required for dural puncture with different spinal needles and subsequent leakage of cerebrospinal • uid. Anesth Analg 1994;79:769-72.

[20]. Veena R Shah, Guruprasad P Bhosale et al Spinal Anaesthesia in Young Patients: Evaluation of Needle Gauge and Design on Technical Problems and Postdural Puncture Headache;South Afr J Anaesth Analg: ISSN (Print): 2220-1181, ISSN (Web): 22201173

[21]. Cruickshank RH, Hopkison JM, fluid flow through dural puncture site ;An in vitro comparison of needle point types . Anesthesia 1989;44:415-8.

[22]. Hwang JJ, Ho ST, Wang JJ, Liu HS. Post dural puncture headache in cesarean section: Comparison of 25-gauge Whitacre with 25and 26-gauge Quincke needles.Acta Anesthesiol Sin. 1997;35:33-7. [PubMed]

[23]. Vallejo MC, Mandell GL, Sabo DP, Ramanathan S. Post-dural puncture headache: A randomized comparison of five spinal needles in obstetric patients. Anesth Analg.2000;91:916-20. [PubMed]

[24]. Kang SB, Goodnough DE, Lee YK, et al. Comparison of 26- and 27-G needles for spinal anesthesia for ambulatory surgery patients. Anesthesiology 1992;76:734-8. 37. Santanen U, Rautoma P, Luurila H, et al. Com5.

[25]. Bano F, Haider S, Aftab S, Sultan ST. Comparision of 25-gauge, Quincke and Whitacre needles for postdural puncture headache in obstetric pstients. J Coll Physicians Surg Pak 2004; 14(11): 647-50.

[26]. Vishal Joshi et al Comparitive Study of 22, 23 and 25 Gauge Quincke Needles for Post Dural Puncture Headache(Pdph) INDIAN JOURNAL OF RESEARCH; Volume : 5 | Issue : 1 | January 2016 
[27]. Muhamad SK, Ghulam NM ,Safia MS, Maqsood AS . Post dural headache in obstetric : a comparative study using 25 G whitacre \& 27 G Quincke needle. Medical Channel July - sept $2007 ; 13$ (3); $45-8$.

Details of Authors

[1]. Dr. Simeen Usmani. MBBS. DNB (Anaesth). Asstt. Professor. AKT College A.M.U. Aligarh.

[2]. Dr. Jamal Azmat.* MBBS. MD (Medicine). Asstt .Professor. AKT College A.M.U. Aligarh

[3]. Dr. Shaeen Jameel. MBBS. MD (Anaesth). Professor. AKT College A.M.U. Aligarh.

[4]. Dr.Sirajuddin. P.G Student. AKT College A.M.U. Aligarh. 